\title{
Application Of Optimization Of Sunco Cooking Oil Planning In Alfamidi Minimarket Using Tsukamoto Method
}

\section{Penerapan Optimasi Perencanaan Persediaan Minyak Goreng Sunco Di Minimarket Alfamidi Menggunakan Metode Tsukamoto}

\author{
Mochamad Andre Firdiansyah ${ }^{1}$, Boy Isma Putra ${ }^{2}$ \\ andrefirdi24@gmail.com ${ }^{1}$, boyisma@umsida.ac.id $\left.{ }^{2}\right\}$ \\ Prodi Teknik Industri Fakultas Sains dan Teknologi Universitas Muhammadiyah Sidoarjo \\ Jl. Raya Gelam No.250, Gelam, Kec. Candi, Sidoarjo
}

\begin{abstract}
Alfamidi is a minimarket that sells fresh good products, frozen food processed meat that is needed by the public. An example of the product under study was in the form of 2 liter packaged sunco cooking oil. This study aims to predict the stock of goods not in line with sales of goods because customer demand is not always the same or uncertain for each item. Therefore it is necessary to predict the addition of stock of goods so that the addition of stock of goods is more in line with sales of goods. The step to solve this problem in this research is by using the Tsukamoto method the optimum value of the 2-liter packaged SunCo cooking oil product supply can be obtained. The first thing that is done using the Tsukamoto method is to make the process of combining 9 fuzzy sets as follows: Decreasing demand, Fixed demand, Increasing demand, Low supply, Medium inventory, Decreasing delivery of goods, Fixed goods delivery and Increasing goods shipments and determining crisp output. In the existing condition of Alfamidi minimarkets with 2 liter Sunco products, the demand for shipping goods is always excessive. So that in the Tsukamoto method, each consequent in the IF-THEN form must be represented by a fuzzy set with a monotonous membership function. As a result, the inference result of each rule is given crisp based on the $\alpha$-predicate (fire strength). The final result uses a weighted average. So that it can be analyzed the stock of 2 liter packaged Sunco cooking oil that must be sent in November, namely 673 packs.
\end{abstract}

Keywords - Production Planning; Inventory Management; Tsukamoto Method

Abstrak. Alfamidi merupakan minimarket yang menjual barang produk fresh good, daging olahan makanan beku yang dibutuhkan masyarakat. Contoh produk yang diteliti yaitu berupa minyak goreng sunco kemasan 2 liter. Penelitian ini bertujuan untuk meramalkan stok barang tidak selaras dengan penjualan barang karena permintaan pelanggan yang tidak selalu sama atau tidak pasti untuk setiap barang. Oleh karena itu diperlukan prediksi penambahan stok barang sehingga penambahan stok barang lebih selaras dengan penjualan barang. Langkah untuk mengatasi permasalahan tersebut dalam penelitian ini yaitu dengan menggunakan metode Tsukamoto dapat diperoleh nilai optimum jumlah persediaan produk minyak goreng SunCo kemasan 2 liter. Hal pertama yang dilakukan menggunakan metode tsukamoto adalah membuat proses penggabungan 9 himpunan fuzzy sebagai berikut: permintaan Turun, permintaan Tetap, permintaan Naik, persediaan Sedikit, persediaan Sedang, Persediaan Banyak, pengiriman barang Berkurang, pengiriman barang Tetap dan pengiriman barang Bertambah dan menentukan output crisp. Pada kondisi eksisting pada minimarket alfamidi dengan produk sunco kemasan 2 liter permintaan stok barang pengiriman selalu berlebih. Sehingga pada metode Tsukamoto, setiap konsekuen pada aturan yang berbentuk IF-THEN harus direpresentasikan dengan suatu himpunan fuzzy dengan fungsi keanggotaan monoton. Sebagai hasilnya, keluaran hasil inferensi dari tiap-tiap aturan diberikan secara tegas (crisp) berdasarkan $\alpha$-predikat (fire strength). Hasil akhir menggunakan rata-rata terbobot. Sehingga dapat dianalisa stok minyak goreng sunco kemasan 2 liter yang harus dikirim pada bulan november yaitu 673 kemasan.

Kata Kunci - Perencanaan Produksi; Manajemen Produksi; Metode Tsukamoto

\section{Pendahuluan}

PT. Midi Utama Indonesia Tbk. adalah pabrik yang beralih dibidang jasa penyediaan produk yang di Pasuruan, sekaligus gudang yang ada di area Pasuruan. PT. Midi Utama Indonesia Tbk.adalah gudang dari seluruh minimarket alfamidi dan alfa Express.

Pada perusahaan Midi Utama Indonesia ini masalah yang timbul adalah gudang barang suatu perusahaan memiliki stock atau persediaan minyak goreng sunco kemasan 2 liter selalu bertambah tiap bulan dengan rate ratarata 100 dan rata-rata kelebihan stock sebesar 107 kemasan. Penelitian yang dilakukan menggunakan metode Tsukamoto dapat diperoleh nilai optimum jumlah persediaan produk minyak goreng SunCo kemasan 2 liter. Dengan menggunakan Sistem Inferensi Fuzzy yaitu suatu kerangka komputasi yang didasarkan pada teori himpunan fuzzy, 
aturan fuzzy berbentuk $I F-T H E N$, dan penalaran fuzzy. Selama ini telah dikenal beberapa metode dalam FIS, seperti metode Tsukamoto, metode Mamdani dan metode Sugeno. Pada metode Tsukamoto, setiap konsekuen pada aturan yang berbentuk IF-THEN harus direpresentasikan dengan suatu himpunan fuzzy dengan fungsi keanggotaan monoton. Sebagai hasilnya, keluaran hasil inferensi dari tiap-tiap aturan diberikan secara tegas (crisp) berdasarkan $\alpha$-predikat (fire strength). Hasil akhir menggunakan rata-rata terbobot.

Penelitian ini bertujuan untuk mengetahui jumlah persediaan minyak goreng sunco kemasan 2 liter yang optimum tiap bulannya untuk memenuhi permintaan minimarket alfamidi.

\section{A. Minyak Goreng}

\section{Tinjauan Pustaka}

Minyak goreng minyak yang berasal dari pemurnian bagian tumbuhan, hewan yang biasanya digunakan untuk menggoreng makanan. Pada umumnya minyak goreng merupakan salah satu bahan pangan pokok yang penting bagi masyarakat guna memenuhi kebutuhan sehari-hari. Konsumsi minyak goreng masyarakat terbagi dalam dua kategori yaitu minyak goreng curah dan kemasan. Minyak goreng curah adalah minyak goreng yang tidak memiliki merek dan diukur dalam satuan massa (kilogram). Minyak goreng kemasan adalah minyak goreng yang diberi merek dan dikemas dengan botol, plastik refill, dan jerigen dan diukur dalam satuan volume (liter).Tiap jenis minyak goreng memiliki kadar lemak tak jenuh (lemak baik) dan lemak jenuh (lemak jahat) yang berbeda-beda. Banyak kita temukan masyarakat lebih memilih mengkonsumsi minyak goreng curah karena harga yang terjangkau murah dibandingkan minyak goreng dalam kemasan.Akibatnya dari mereka mudah terkena penyakit karena minyak goreng curah memiliki kualitas dan higienitas yang buruk.

Minyak goreng adalah minyak nabati yang telah dimurnikan dan dapat digunakan sebagai bahan pangan. Minyak goreng merupakan salah satu dari sembilan bahan pokok yang dikonsumsi oleh seluruh lapisan masyarakat. Konsumsi minyak goreng biasanya digunakan sebagai media menggoreng bahan pangan, penambah cita rasa, ataupun shortening yang membentuk tekstur pada pembuatan roti. Minyak goreng yang baik mempunyai sifat tahan panas, stabil pada cahaya matahari, tidak merusak flavor hasil gorengan, sedikit gum, menghasilkan produk dengan tekstur dan rasa yang bagus, asapnya sedikit setelah digunakan berulang-ulang, serta menghasilkan warna kemasan pada produk.

Minyak goreng curah umumnya hanya menggunakan satu kali proses penyaringan, sehingga masih mengandung fraksi padat stearin yang relatif lebih banyak dari minyak goreng bermerek yang menggunakan dua kali proses penyaringan. Oleh karena itu minyak goreng curah tidak sejernih minyak goreng bermerek. Hal ini berkaitan dengan titik cair (suhu pada saat lemak mulai mencair) dan cloud point (suhu pada saat mulai terlihat adanya padatan) pada minyak. Dari segi kandungan, kadar lemak dan asam oleat dari minyak curah lebih tinggi dibanding dengan minyak kemasan. Namun tidak ada masalah menggunakan minyak curah, asal tidak berlebihan dan tidak digunakan berulang sampai berwarna kehitam-hitaman.Karena pemakaian berulang-ulang pada minyak curah sangat tidak baik bagi kesehatan [1].

\section{B. Persediaan}

Persediaan (Inventory) adalah suatu istilah umum yang menunjukan segala sesuatu atau sumber daya-sumber daya organisasi yang disimpan dalam antisipasinya terhadap pemenuhan permintaan [2].

Persediaan merupakan suatu aktiva yang meliputi barang-barang milik perusahaan dengan maksud untuk dijual dalam suatu periode usaha tertentu atau persediaan barang-barang yang masih dalam pengerjaan atau proses produksi ataupun persediaan bahan baku yang menunggu penggunaannya dalam proses produksi [3].

Fungsi persedian dilihat dari 4 alasan berikut :

1. Faktor waktu (Time Factor) menyangkut lamanya proses produksi dan distribusisebelum barang jadi kepada konsumen.waktu yang diperlukan untuk pembuatan jadwal produksi.

2. Faktor ketidakpastian waktu datang (The Discontinuty Factor) ketidakpastian supplier yang menyebabkan perusahaan memerlukan adanya persediaan agar tidak menyebabkan keterlambatan produksi atau pengiriman barang ke konsumen. Persediaan barang baku tergantung supplier persediaan barang agar ketidakpastian waktu datang bias teratasi maka dari itu perusahan mengharuskan membuat jadwal oprasi yang lebih teliti pada setiap level.

3. Faktor ketidakpastian penggunaan (The Uncertainty Factor) dalam perusahaan ketidakpastian penggunaan disebabkan oleh kesalaan peramalan permintaan, kerusakan mesin, keterlambatan proses produksi, bahan cacat dan berbagai kondisi lainya.

4. Faktor ekonomis (The Economy Factor) adanya keinginan perusahaan untuk mendapatkan alternatif biaya rendah dalam membeli dan memproduksi barang dengan menentukan jumlah yang paling ekonomis.

Tujuan utama dari persediaan yaitu untuk mendapatkan jumlah yang tepat untuk barang yang dipesan di tempat yang tepat, waktu yang tepat dan biaya yang minimum. Terdapat beberapa komponen biaya yang dapat digunakan dalam sistem persediaan yaitu [4] :

a. Biaya pembelian (purchase cost)

b. Biaya pemesanan (order cost atau setup cost)

c. Biaya simpan (holding cost), yang terdiri atas: 


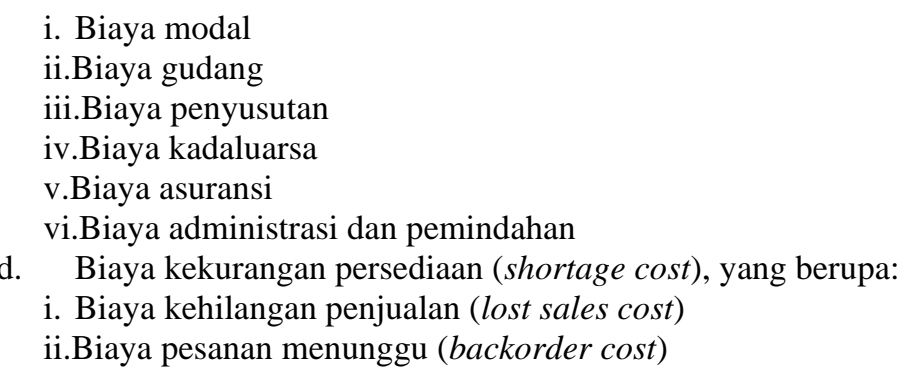

\section{Pengendalian Persediaan}

pengendalian persediaan terdapat berbagai jenis model yang dapat digunakan untuk perencanaan dan pengendalian[4] .

Secara umum, model persediaan dapat dikelompokkan menjadi dua yaitu:

a. Model deterministik, yang ditandai oleh karakteristik permintaan dan periode kedatangan yang dapat diketahui secara pasti sebelumnya.

b. Model probabilistik, yang ditandai oleh karakteristik permintaan dan periode kedatangan pesanan yang tidak dapat diketahui secara pasti sebelumnya, sehingga perlu didekati dengan distribusi probabilitas.

\section{Perencanaan Agregat}

Perencanaan agregat merupakan perencanaan produksi yang meliputi jumlah unit dan tingkat tenaga kerja yang diperlukan dan diharap dapat memenuhi angka permintaan yang bervariasi pada suatu periode tertentu. Perencanaan agregat tergolong ke dalam perencanaan jangka menengah, yang artinya hasil dari perencanaan ini baik untuk digunakan dalam kurun waktu 3-18 bulan ke depan. Dalam perencanaan agregat, perencanaan tidak berfokus kepada produk secara individu melainkan secara agregat sehingga diperlukan adanya suatu proses agregasi. Proses agregasi dilakukan dengan melakukan pengelompokkan kepada produk-produk yang sejenis dalam satu family. Dalam perencanaan produksi ini tidak berfokus kepada produk serta individu melainkan secara perencanaan sehingga diperlukan adanya suatu proses agregasi. Proses agregasi dilakukan dengan melakukan pengelompokan kepada produk yang sejenis dalam satu keluarga. Dalam perencanaan agregat ada dua strategi yang dapat digunakan yatitu level strategy dan chase strategy. Terdapat tiga metode yang juga dapat digunakan untuk menyusun sebuah perencanaan agregat, yaitu metode Cut and Try, Transportation Model dan Linear Programming [5].

\section{E. Peramalan}

Peramalan adalah proses untuk memperkirakan berapa kebutuhan dimasa yang akan datang yang meliputi kebutuhan dalam ukuran kuantitas, kualitas, waktu dan lokasi yang dibutuhkan dalam rangka memenuhi permintaan barang ataupun jasa. Peramalan tidak terlalu dibutuhkan dalam kondisi permintaan pasar yang stabil, karena perubahan permintaannya relatif kecil. Tetapi peramalan akan sangat dibutuhkan bila kondisi permintaan pasar bersifat komplek dan dinamis[6].

Peramalan dibagi menjadi dua bagian yaitu peramalan kualitatif dan peramalan kuantitatif. Metode peramalan kualitatif lebih mendasarkan kualitatif dimasa lalu yaitu ramalan dikatakan baik atau tidaknya bergantung dari banyak hal antara lain pengalaman, perkiraan dan pengetahuan yang didapat. Metode peramalan kuantitatif itu sendiri merupakan peramalan yang didasarkan pada data kuantitatif dimasa lalu. Dalam melakukan peramalan, hasil yang didapatkan tidak selalu tepat sesuai dengan kenyataan

\section{F. Logika Fuzzy}

Logika fuzzy secara bahasa diartikan kabur atau samar-samar. Dalam fuzzy dikenal derajat keanggotaan yang memiliki rentang nilai 0 sampai 1. Berbeda dengan himpunan tegasa yang memiliki nilai 1 atau 0 (ya atau tidak). Logika fuzzy merupakan suatu logika yang memiliki nilai kekaburan atau kesamaran (fuzzyness) antara benar atau salah. Dalam teori logika fuzzy suatu nilai bisa bernilai benar atau salah secara bersamaan. Namun seberapa besar kebenaran atau kesalahan itu tergantung pada bobot keanggotaanyang dimilikinya[7].

\section{G. Fungsi Keanggotaan}

Fungsi keanggotaan adalah suatu kurva yang menunjukkan pemetaan titik-titik input data ke dalam nilai keanggotaannya (sering juga disebut dengan derajat keanggotaan) yang terletak pada interval antara 0 sampai. Fungsi keanggotaan pada himpunan fuzzy yang sering digunakan adalah fungsi keanggotaan segitiga dan trapesium. Pada tulisan ini hanya akan dibahas mengenai fungsi keanggotaan trapesium[8].

\section{H. Metode Tsukamoto}

Dalam membangun sebuah sistem fuzzy dikenal beberapa metode penalaran, antara lain : metode Tsukamoto, metode Mamdani dan metode Sugeno.

Pada metode Tsukamoto, setiap konsekuen pada aturan berbentuk IF-THEN harus direpresentasikan dengan suatu himpunan fuzzy dengan fungsi keanggotaan monoton. Sebagai hasilnya, output hasil inferensi dari tiap-tiap aturan diberikan dengan tegas (crisp) berdasarkan $\alpha$-predikat (fire strength). Hasil akhirnya diperoleh dengan menggunakan rata-rata terbobot. 
Misal ada 2 variabel input, var-1(x) dan var2(y) serta 1 variabel output var-3(z), dimana var-1 terbagi atas 2 himpunan yaitu A1 dan A2 dan var-2 terbagi atas himpunan B1 dan B2. Sedangkan var-3 juga terbagi atas 2 himpunan yaitu $\mathrm{C} 1$ dan $\mathrm{C} 2[9]$.

Pada metode tsukamoto, setiap konsekuensi pada aturan yang berbentuk IF-THEN harus dipresentasikan dengan suatu himpunan fuzzy dengan fungsi keanggotaanyang monoton. Setiap hasilnya, output hasil inferensi dari tiap-tiap aturan diberikan secara tegas (crisp) berdasarkan $\alpha$-predikat (fire strength). Hasil akhirnya diperoleh dengan menggunakan rata-rata terbobot[10].

\section{Forward Chaining}

Algoritma forward-chaining adalah satu dari dua metode utama reasoning (pemikiran) ketika menggunakan inference engine (mesin pengambil keputusan) dan bisa secara logis dideskripsikan sebagai aplikasi pengulangan dari modus ponens (satu set aturan inferensi dan argumen yang valid). Lawan dari forward-chaining adalah backward-chaining.

Forward-chaining mulai bekerja dengan data yang tersedia dan menggunakan aturanaturan inferensi untuk mendapatkan data yang lain sampai sasaran atau kesimpulan didapatkan. Mesin inferensi yang menggunakan forwardchaining mencari aturan-aturan inferensi sampai menemukan satu dari antecedent (dalil hipotesa atau klausa IF - THEN) yang benar. Ketika aturan tersebut ditemukan maka mesin pengambil keputusan dapat membuat kesimpulan, atau konsekuensi (klausa THEN), yang menghasilkan informasi tambahan yang baru dari data yang disediakan. Mesin akan mengulang melalui proses ini sampai sasaran ditemukan.

Forward-chaining adalah contoh konsep umum dari pemikiran yang dikendalikan oleh data (data-driven) yaitu, pemikiran yang mana focus perhatiannya dimulai dari data yang diketahui. Forward-chaining bisa digunakan didalam agen untuk menghasilkan kesimpulan dari persepsi-persepsi yang datang, seringkali tanpa query yang spesifik[11].

\section{J. Backward Chaining}

Backward chaining adalah suatu alasan berkebalikan dengan hipotesis, dimana hipotesis dihasilkan setelah mengumpulkan fakta \pm fakta yang sudah ada secara lengkap lalu diambil kesimpulan (conclusion) atau hipotesisnya sedangkan backward chaining akan memperkirakan potensial kesimpulan (conclusion) yang mungkin terjadi atau terbukti, karena adanya fakta yang mendukung hipotesis tersebut[12]. berikut :

Sebagai contoh akan diuraikan sebagai berikut, jika suatu masalah mempunyai sederetan kaidah seperti

$\mathrm{R} 1: \mathrm{A} A N D \mathrm{C}, T H E N \mathrm{E}$

R2 : IF D AND C, THEN F

$\mathrm{R} 3: I F$ B AND E, THEN F

$\mathrm{R} 4: I F$ B THEN C

$\mathrm{R} 5$ : IF F THEN G

Fakta yang diketahui adalah A dan B bernilai benar (True). Proses Penalaran yang akan dilakukan adalah :

Langkah 1 : Berdasarkan R5 jika F bernilai benar maka G bernilai Benar, maka kita akan menelusuri aturan yang terdapat variabel F yaitu R2 dan R3.

Langkah 2 : Pada aturan R2 kita tidak mengetahui nilai kebenaran D karena tidak disebutkan pada fakta yang diketahui dan juga tidak ada rule lagi selain rule itu sendiri untuk mengetahui nilai kebenaran $\mathrm{D}$, maka selanjutnya kita akan mengevaluasi R3.

Langkah 3 : Pada aturan R3 dapat diketahui sesuai dengan fakta acuan bahwa B bernilai benar maka kita akan menelusuri aturan yang terdapat variabel E yaitu R1

Langkah 4 : Berdasarkan R1 maka dapat diketahui bahwa A adalah bernilai benar maka selanjutnya kita akan menelusuri aturan yang terdapat variabel $\mathrm{C}$ yaitu $\mathrm{R} 4$

Langkah 5: Berdasarkan R4 maka dapat diketahui bahwa $\mathrm{C}$ bernilai benar karena B bernilai benar. 


\section{METODE PENELITIAN}

Menjelaskan tentang kegiatan selama proses penelitian dari mulai studi pustaka, studi lapangan, pengumpulan data, dan analisa data sampai dengan akhir proses penelitian. Berikut ini merupakan gambar dari flow chart penelitian yang terlihat pada gambar 1 .

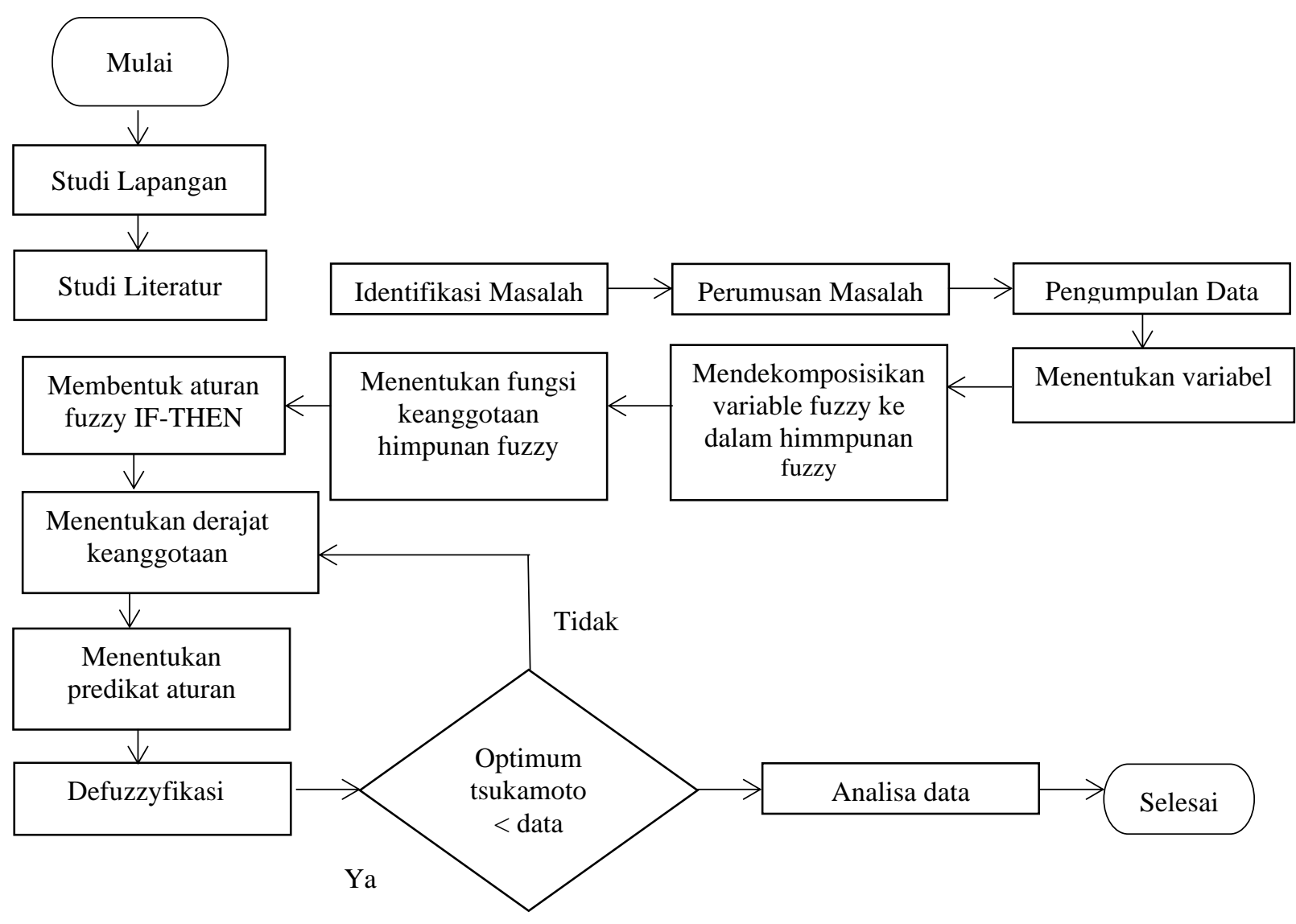

Gambar. 1 Diagram Alir Penelitian

\section{A. Analisa Data Menggunakan Metode Tsukamoto}

\section{Hasil dan Pembahasan}

Dalam menyelesaikan permasalahaan tersebut diatas dengan menggunakan metode Tsukamoto secara manual, ada beberapa langkah yang ditempuh. Langkah-langkah tersebut adalah: mendefinisikan variabel fuzzy, inferensi, dan defuzifikasi (menentukan output crisp).

\section{[R1] IF Permintaan TURUN And Persediaan BANYAK THEN Pengiriman Barang BERKURANG;}

Nilai keanggotaan anteseden untuk aturan fuzzy [R1] yang dinotasikan dengan $\alpha_{1}$ diperoleh dengan rumus sebagai berikut:

$$
\begin{aligned}
\alpha_{1} & =\mu_{\text {PmtTURUN }} \quad \\
& =\min \left(\mu_{\text {PmtTURUN }}[800] . \mu_{\text {PsdBANYAK }}[70]\right) \\
& =\min (0.125 ; 0.66) \\
& =0.125 \\
& =900-0.125(900-400) \\
z_{1} & =837,5
\end{aligned}
$$

[R2] IF Permintaan TURUN And Persediaan SEDANG THEN Produksi Barang BERKURANG;

Nilai keanggotaan anteseden untuk aturan fuzzy [R2] yang dinotasikan dengan $\alpha_{2}$ diperoleh dengan rumus sebagai berikut:

$$
\begin{aligned}
\alpha_{2} & =\mu_{\text {PmtTURUNกPSdSEDANG }} \\
& =\min \left(\mu_{P \operatorname{miTURUN}}[800] . \mu_{\text {PSdSEDANG }}[70]\right) \\
& =\min (0.125 ; 0.66) \\
& =0.125 \\
z_{2} & =900-0.125(900-400)
\end{aligned}
$$




$$
=837.5
$$

[R3] IF Permintaan TURUN And Persediaan SEDIKIT THEN Pengiriman Barang BERKURANG;

Nilai keanggotaan anteseden untuk aturan fuzzy [R3] yang dinotasikan dengan $\alpha_{3}$ diperoleh dengan rumus sebagai berikut:

$$
\begin{aligned}
\alpha_{3} & =\mu_{\text {PmtTURUNกPSdSEDIKIT }} \\
& =\min \left(\mu_{\text {PmtTURUN }}[800] \cdot \mu_{\text {PSASEDIKIT }}[70]\right) \\
& =\min (0.125 ; 0.33) \\
& =0.125 \\
& =900-0.125(900-400) \\
& =837.5
\end{aligned}
$$

[R4] IF Permintaan TETAP And Persediaan BANYAK THEN Pengiriman Barang BERKURANG;

Nilai keanggotaan anteseden untuk aturan fuzzy [R4] yang dinotasikan dengan $\alpha_{4}$ diperoleh dengan rumus sebagai berikut:

$$
\begin{aligned}
\alpha_{4} & =\mu_{P m t T E T A P \cap P S d B A N Y A K} \\
& =\min \left(\mu_{P \operatorname{PmTETAP}}[800] . \mu_{\text {PSdBANY AK }}[70]\right) \\
& =\min (0.25 ; 0.66) \\
& =0.25 \\
& =900-0.25(900-400) \\
z_{4} & =775
\end{aligned}
$$

[R5] IF Permintaaan TETAP And Persediaan SEDANG THEN Pengiriman Barang TETAP;

Nilai keanggotaan anteseden untuk aturan fuzzy [R5] yang dinotasikan dengan $\alpha_{5}=0,25$. Karena pengiriman barang TETAP, maka tampak $\mathrm{z}_{5}=\mathrm{z}_{\mathrm{t}}=650$

[R6] IF Permintaan TETAP And Persediaan SEDIKIT THEN Pengiriman Barang BERTAMBAH;

Nilai keanggotaan anteseden untuk aturan fuzzy [R6] yang dinotasikan dengan $\alpha_{6}$ diperoleh dengan rumus sebagai berikut:

$$
\begin{aligned}
\alpha_{6} & =\mu_{\text {PmtTETAPกPSdSEDIKIT }} \\
& =\min \left(\mu_{\text {PmtTETAP }}[800] \cdot \mu_{\text {PSdSEDIKIT }}[70]\right) \\
& =\min (0.25 ; 0.33) \\
& =0.25 \\
z_{6} & =0.25(900-400)+400 \\
& =525
\end{aligned}
$$

[R7] IF Permintaan NAIK And Persediaan BANYAK THEN Pengiriman Barang BERTAMBAH:

Nilai keanggotaan anteseden untuk aturan fuzzy [R7] yang dinotasikan dengan $\alpha_{7}$ diperoleh dengan rumus sebagai berikut:

$$
\begin{aligned}
\alpha_{7} & =\mu_{P m T N A I K \cap P S d B A N Y A K} \\
& =\min \left(\mu_{P m E N A I K}[800] . \mu_{P S d B A N Y A K}[70]\right) \\
& =\min (0.75 ; 0.66) \\
& =0.66 \\
& =0.66(900-400)+400 \\
& =730
\end{aligned}
$$

[R8] IF Permintaan NAIK And Persediaan SEDANG THEN Pengiriman Barang BERTAMBAH;

Nilai keanggotaan anteseden untuk aturan fuzzy [R8] yang dinotasikan dengan $\alpha_{8}$ diperoleh dengan rumus sebagai berikut:

$$
\begin{aligned}
\alpha_{8} & =\mu_{P m t N A I K \cap P S d S E D A N G} \\
& =\min \left(\mu_{P m E N A I K}[800] \cdot \mu_{P S d S E D A N G}[70]\right) \\
& =\min (0.75 ; 0.66) \\
& =0.66 \\
z_{8} & =0.66(900-400)+400 \\
& =730
\end{aligned}
$$

[R9] IF Permintaan NAIK And Persediaan Barang SEDIKIT THEN Pengiriman Barang BERTAMBAH;

Menurut fungsi keanggotaan himpunan Pengiriman Barang BERTAMBAH dalam aturan fuzzy [R9] pada persamaan 4.18 maka nilai $\mathrm{z} 9$ adalah:

$$
\begin{aligned}
\alpha_{9} & =\mu_{P m L N A I K \cap P S d S E D I K I T} \\
& =\min \left(\mu_{P m t N A I K}[800] . \mu_{P S d S E D A N G}[70]\right) \\
& =\min (0.75 ; 0.33) \\
& =0,33
\end{aligned}
$$




$$
\begin{aligned}
z_{9} & =0.33(900-400)+400 \\
& =565
\end{aligned}
$$

\section{B. Menentukan Output Crisp (Deffuzzyfikasi)}

Pada metode tsukamoto, untuk menentukan output crisp digunakan defuzifikasi rata-rata terpusat, yaitu:

$$
Z=\frac{\alpha 1 \times z 1+\alpha 2 \times z 2+\alpha 3 \times z 3+\alpha 4 \times z 4+\alpha 5 \times z 5+\alpha 6 \times z 6+\alpha 7 \times z 7+\alpha 8 \times z 8+\alpha 9 \times z 9}{\alpha 1+\alpha 2+\alpha 3+\alpha 4+\alpha 5+\alpha 6+\alpha 7+\alpha 8+\alpha 9}
$$

$Z$

$$
\begin{aligned}
& =\frac{0.125 \times 837.5+0.125 \times 837.5+0.125 \times 837.5+0.25 \times 775+0.25 \times 650+0.25 \times 525+0.66 \times 730+0.66 \times 730+0}{0.125+0.125+0.125+0.25+0.25+0.25+0.66+0.66+0.33} \\
& Z=\frac{104.68+104.68+104.68+193.75+162.5+131.25+481.8+481.8+186.45}{2.9}
\end{aligned}
$$

$Z=\frac{1951.59}{2.9}$

$\mathrm{Z}=672,9$

Jadi, menurut perhitungan dengan metode Tsukamoto diatas, jumlah minyak SunCo yang harus dikirim kepada minimarket Alfamidi pada bulan November sebanyak 672-673 kemasan.

\section{KESIMPULAN}

Kesimpulan penelitian ini adalah sebagai berikut:

Dari perhitungan bab-bab sebelumnya dapat disimpulkan ratae rata-rata persediaan tiap bulannya mengalami peningkatan 100 stok dan pada pengiriman bulan November sebesar 673 kemasan.

\section{REFERENSI}

[1] E. Juliana, "Perbedaan Indeks Bias Minyak Goreng Curah Dengan Minyak Goreng Kemasan Bermerek Sunco (Index Difference With Bias Cooking Oil Cooking Oil Bulk Packaging Branded Sunco) Oleh," J. Fis. Edukasi, vol. 2, no. 2, pp. 76-80, 2015.

[2] E. Ruauw, "Pengendalian Persediaan Bahan Baku," Ase, vol. 7, no. 1, pp. 1-11, 2011.

[3] E. P. Lahu et al., "Analisis Pengendalian Persediaan Bahan Baku Guna Meminimalkan Biaya Persediaan Pada Dunkin Donuts Manado," J. EMBA J. Ris. Ekon. Manajemen, Bisnis dan Akunt., vol. 5, no. 3, pp. 4175-4184, 2017, doi: 10.35794/emba.v5i3.18394.

[4] B. S. Istiqomah and I. A. Marie, "Perbaikan Kebijakan Pengendalian Persediaan Just in Time Komponen Produk Main Floor Side Lh Pada Pt Gaya Motor," J. Ilm. Tek. Ind. ISSN 1412-6869. Univ. Trisakti, Jakarta, vol. 14, no. 1, pp. 66-77, 2015.

[5] D. Kurniawan and T. Octavia, "Perencanaan Produksi dengan Mempertimbangkan Kapasitas Produksi pada CV . X,” J. Titra, vol. 5, no. 2, pp. 315-320, 2017.

[6] H. A. Nasution, Perencanaan \& Pengendalian Persediaan, Ke-1. Surabaya: Penerbit Guna Widya, 1999.

[7] V. Devani, "Optimasi Komposisi Kandungan Nutrisi Pakan Ikan Buatan dengan Menggunakan Fuzzy Linear Programming," J. Tek. Ind. J. Has. Penelit. dan Karya Ilm. dalam Bid. Tek. Ind., vol. 5, no. 1, p. 20, 2020, doi: 10.24014/jti.v5i1.6160.

[8] S. Basriati, E. Safitri, and R. Y. H. M, “Optimasi Hasil Produksi Model Fuzzy Linear Programming (FLP) Menggunakan Metode Mehar (Studi Kasus: Usaha Uni Risna Payakumbuh),” J. Sains Mat. dan Stat., vol. 5, no. 2, pp. 90-99, 2019.

[9] H. S. Permatasari, A. Suyatno, and A. H. Kridalaksana, "Sistem Pendukung Keputusan Pemilihan Program Studi Di Universitas Mulawarman Menggunakan Metode Tsukamoto (Studi Kasus : Fakultas MIPA)," Inform. Mulawarman J. Ilm. Ilmu Komput., vol. 10, no. 1, p. 32, 2016, doi: 10.30872/jim.v10i1.19.

[10] H. P. Sri Kusumadewi, Aplikasi Logika Fuzzy Untuk Pendukung Keputusan, Ke-1. Yogyakarta: Graha Ilmu, 2018.

[11] I. Akil, “Analisa Efektifitas Metode Forward Chaining Dan,” J. Pilar Nusa Mandiri, vol. 13, no. 1, pp. 3542, 2017.

[12] A. C. M.Yusuf Efendy, Sandro Alfeno, "Penerapan Backward ChainingSebagai Model Criminal Investigation Expert System(CRIES) Untuk Menangani Kasus Pembunuhan,” J. Sisfotek Glob., vol. 6, no. 2, 
Procedia of Engineering and Life Science Vol.1 No. 2 Juni 2021

Seminar Nasional \& Call for Paper Fakultas Sains dan Teknologi (SENASAINS 2nd)

Universitas Muhammadiyah Sidoarjo

p. 70, 2016, [Online]. Available: https://media.neliti.com/media/publications/297734-penerapan-backwardchaining-sebagai-mode-e1bf5fd8.pdf. 